\title{
Technical and Non-Technical Factors of Risk Identification for Sustainable Coastal Development in Malaysia
}

\author{
Mohd Azrulfitri Azimi ${ }^{1}$, Sharifah Akmam Syed Zakaria ${ }^{2}$, Taksiah A. Majid ${ }^{3}$ \\ School of Civil Engineering, Engineering Campus, Universiti Sains Malaysia, Penang, Malaysia ${ }^{1,2,3}$
}

\begin{abstract}
In recent years, human casualties and economic losses caused by natural disasters in Malaysia have been increasing, with infrastructure development is becoming concentrated in disaster-prone areas. Urbanized coastal cities are also growing in number and size with high-rise buildings widely built along the shorelines. Every community is at risk from natural hazards, which creates an urgent need for public policies and strategic plans to manage the inevitable risks. Thus, this study aims to explore the technical and nontechnical factors of disaster risks pertaining infrastructure development for sustainability along the coastal areas of Malaysia. It is also intended to find the common aspects of these technical and non-technical factors that can be built as an integral part of disaster risk management. Specifically, this study presents evidence using a quantitative analysis for classifying and ranking technical and non-technical factors of disaster risks from an open-ended feedback on a given hypothetical case study pertaining infrastructure development along coastal areas. The results reflect that the technical factors of disaster risks include engineering measures and construction of hazard-resistant and protective infrastructures, while the non-technical-factors include policies, awareness and the provision of information. Determining the risk factors that enable communities and policy makers make well-informed decisions for long-term sustainable development represents national and local priorities with a strong institutional basis for implementation.
\end{abstract}

Keywords_Disaster risk, Risk factors, Sustainable coastal development

\section{INTRODUCTION}

$\mathrm{N}$ atural hazards such as earthquakes, floods, tsunamis, cyclones and forest fire resulted to disasters which have caused significant impacts to development [1]. Human casualties and economic losses because of floods and tsunamis in Malaysia's context is on the rise in recent years, indicating infrastructure development of the area are becoming concentrated in disaster-prone areas. On top of that, reported rate of occurrences of such events are also on the rise especially in the case of major flood events. Data collected since 1920 have shown that a total number of 24 occurrences of major flood events in Malaysia which have caused billions of Ringgits of economic losses along with millions of people left being homeless although the death toll may not be as catastrophic if compared to deadly events such as earthquake or hurricane [2]-[5]. Urbanized coastal cities are also growing in number and size with high-rise buildings widely built along the shorelines. It is believed that coastal areas are highly populated in many parts of the world with an estimated $40.00 \%$ of the population resides within 100 Kilometers from the coastline and this figures is projected to increase further in the future [6][7]. It was revealed by the United Nations in 2015 that over the past 10 years, significant mortality and economic losses have been suffered because of natural disasters whereby total economic losses recorded for the period was more than $\$ 1.3$ trillion. Additionally, more than 700,000 people lost their lives and around 23 million of people were left homeless [8]. Therefore, it can be stated that natural disaster has been recognized as a serious, life threatening and costly cause for worldwide concern as every community is at risk from natural hazards, which creates an urgent need for public policies and strategic plans to manage the inevitable risks.

\subsection{Significance of Study}

Over the years, researches on disaster risk have been building up studies on various fields such as disaster risk reduction, post-disaster reconstruction, disaster risk mitigation, capacity building and vulnerability assessment in coastal areas. United Nations on the other hand introduced Sendai Framework for Disaster Risk Reduction (2015-2030) in 2015, a follow-up of the Hyogo Framework for Action (2005-2015) issued in 2005 , as part of continuous global efforts to reduce risks and impacts of natural disaster posed towards the wellbeing of the society as well as to the environment. Although many researchers have managed to identify the underlying factors in which disaster risks are perceived by the public, there was no literature known to have categorizing these factors into technical and nontechnical variables. This is crucial in disaster management because by understanding the technical and non-technical factors of disaster risk (which form major part of the vulnerability assessment), it will enable a more effective decision-making process and helps in the formation of more holistic and resourceful policies that will support the sustainable development efforts especially in coastal areas. Hence, this study will seek to explore the technical and non-technical factors of disaster risks pertaining infrastructure development for sustainability along the coastal areas of Malaysia. It is also intended to find the common aspects of these technical and non-technical factors that can be built as an integral part of disaster risk management. 


\section{LITERATURE REVIEW}

Disaster risk is defined by the United Nations as "the potential disaster losses, in lives, health status, livelihoods, assets and services, which could occur to a particular community or a society over some specified future time period" [9]. In order to identify and understand risk, in depth study on the social and development factors that contributes to disaster risk should be considered [10]. For example, in the context of sustainable development in coastal areas, the decision of stakeholders to build a more resilient building structure using weather resistant building materials maybe highly influenced by the risk factors such as natural landscape, economic and past natural hazards events incorporated into the decision-making processes to ensure successful project implementation. According to the disaster risk framework proposed by [11], disaster risk is derived from the interaction of three main factors which are vulnerability, exposure and; weather and climate events. Due to the dynamic nature of exposure and vulnerability, factors such as economic, cultural, environmental, institutional, governance, demographic, geographic and social are found to be influential.

\subsection{Thematic Risk Factor}

[12] Explained vulnerability into three variables which are exposure, sensitivity and resilience with sensitivity having human and environmental factors forming part of the vulnerability framework. [13] used Pressure and Release (PAR) Model to explain disaster risk, where root causes, dynamic pressures and unsafe conditions with physical, economic, social and organizational risk factors formed part of vulnerability assessment. Meanwhile, [14] used exposure and physical susceptibility, socioeconomic fragility as well as lack of social resilience and abilities to cope as part of their vulnerability assessment framework. [15] listed four (4) risk factors of vulnerability in context to sustainable development which are social, economic, physical and environmental. Similarly, [16] and [17] identified the same factors to form part of their vulnerability assessment with addition of factors were then linked with capacity and measures to bridge the measures needed to improve capacities based on these four factors. Lastly, [18] and [19] also listed out economic, social and environmental risk factors as part of their BBC Conceptual Framework for disaster risk with specific focus on sustainable development. In general, vulnerability assessment in the literature reviewed include four main thematic risk factors which are economic, social, physical and environmental and these factors will be used as a base for this research paper. In regard to these four (4) themes, the risk factors identified will be grouped into these relevant themes but not limited to these predetermined themes as results and analysis of the identified technical and non-technical factors of disaster risk will also be based on the common aspects and characteristics that the factors have in nature.

\subsection{Technical Risk Factors}

The environmental, physical, technological as well as health and safety factors are considered as part of the technical risk factors for vulnerability assessment in respect to disaster risk. In regards to environmental risk factors, a study conducted by [20] in Brazil considered environmental risk factor to have dynamic relationships between natural processes, the manufacturing structure, and the social conditions and nature of human population at a given location at a time. Climate change was the central focus by [21] in a study conducted for Central Asia region where human vulnerabilities in the form of food security, water stress and human health are closely linked to the risk factor. Environmental vulnerability was included as part of Environmental Impact Assessment in Colombia and its inclusion was justified by [22] where factors such as wildlife habitat, surface water quality, population, employment education were used as indicators. [23] proposed an environmental vulnerability framework which consists of sensitivity, environmental exposure, adaptive capacity and potential impact to measure the vulnerability indexes for Jakarta, Indonesia. Inundation and pollution were considered as part of the risk factors for environmental exposure while natural systems and human systems were listed as risk factors for sensitivity analysis. While [23] is the only literature reviewed to have proposed a framework to assess the environmental vulnerability, the environmental exposure element didn't take into account risk factors such as natural phenomena, natural landscape and coastal ecosystem as part of their assessment. In regards to physical risk factors, [24] considered physical vulnerability as who and what may be damaged or at risk by natural hazard such as earthquakes or floods. Physical conditions of people and elements at risk such as infrastructure, location and structural resiliency were identified. Physical factors selected by [25] are houses location and elevation, infrastructure conditions, distance of nearest shelter, distance of river and coast from the housing areas, availability and distance of mangroves forest from the villages as part of his vulnerability assessment. [26] identified primary building characteristics, such as construction material and method, along with subsidiary characteristics like the size and frequency of openings in buildings which they considered as important in assessing volcanic eruption impacts when assessing physical risk factors. On the other hand, [27] only considered physical environment and natural hazards impact on built environment as part of their physical vulnerability assessment but did pointed out that the lack of common definition and conceptual framework for vulnerability assessment hinders effective risk reduction efforts. Similarly, physical vulnerability is also ill modelled due reasons such as the lack of observational data on the hazard, the elements at risk and the induced damage, the complexity of the structural damage mechanisms and the chronological and geographical scales [28]. Regarding health and safety risk factor, not many specific literatures were made available especially for safety risk factor. However, [29] identified physical health, mental health and behavioral changes risks as part of vulnerability assessment on health and social dimensions. As for the technological 
risk factor, the same can be said as the amount of literature made available. Alas, [30] discussed the methodology to assess vulnerability in the event of Natural Technological (NaTech) accidents although no specific factor was listed or mentioned for technological risk factor. [20] did mentioned technological risk in their research but the scope was limited to a potential event that can be life-threatening because of investment decisions in the manufacturing structure.

\subsection{Non-Technical Risk Factors}

As for non-technical risk factors, economic, social, socio-cultural, socio-economic and organizational factors are considered. In an investigation into coastal vulnerability in Ireland coast using socio-economic variables, [31] included population, cultural heritage, roads, railways, land use and conservation status as part of their assessment. Economic vulnerability is represented by [32] as exposure of wealth to disaster risk and post-disaster impact to income distribution as part of socio-economic vulnerability assessment. [33] considered economic under-developments, poverty, social inequalities and employment rates as part of their economic vulnerability assessment in Haiti case study. All the literatures referred did not take into the consideration of cost factors such as construction or reconstruction cost and resources factors such as resources availability or resources utilization risk factor as part of the economic vulnerability assessment. Regarding social vulnerability, [34] used variables such as poverty, unemployment, income, age, ethnic (minority), housing and transportation for their assessment. [20] considered the lack of adequate living conditions, expressed in terms of access to necessities such as clean water, waste water management, and waste collection services as social risks as part of their social vulnerability assessment. Lastly, [17] considered poverty, literacy level, attitude, decentralization (ability of community to generate revenue on their own) and community participation as part of their social indicators. As for organizational risks such as policies, awareness and information management, no specific literature found to address this risk factor exclusively as part of vulnerability assessment as elements in this type of risk factor are closely related to the coping capacity and measures for disaster risk. However, [35] did argued that factor such as weak government which form part of political (organizational) vulnerability had influenced disaster risk reduction efforts in Lebanon. The overlapping nature of this type of risk factor has caused it to be maybe overlook by the scholars, be it intentionally or unintentionally. This risk factor will also be identified and explained in the following section. In a whole, the above literatures do provide a platform for a more holistic and extensive identification of risk factors for data analysis in the later section. For disaster risk management to be effective, organizational, economic as well as technological resources should be mobilized to address these main factors.

\section{METHODOLOGY}

Specifically, this study presents evidence using a quantitative analysis for classifying and ranking technical and non-technical factors of disaster risks from an open-ended feedback on a given hypothetical case study pertaining infrastructure development along coastal area. Case study was often used in the field of disaster risk researches with many authors chose to study the unique nature of particular geographical location and/or region and how natural disaster risks impact or perceived in that location. According to [36], among the advantages of using case study are:

- It enables researchers to focus on one or few instances and deal with the delicacies and particulars of complex social situations;

- It allows a more comprehensive understanding of the events being investigated; and

- It allows researchers to observe the relationships and social processes in ways that other methods do not facilitate.

In order to identify and measure technical and nontechnical factors, a scenario was given asking the participants to list five (5) important factors that they consider as crucial regarding disaster risk to ensure the project success in a sustainable development project along the coastal region in Malaysia from the perspective of a future engineer. The project used a sample of 311 students studying engineering courses in Universiti Sains Malaysia (USM), Engineering Campus located in Nibong Tebal, Penang, Malaysia with the respective students specializing in various engineering disciplines such as civil, chemical, mechanical, mechatronic, electrical and electronics and manufacturing. The subjects were selected on the basis of a comprehensive engineering knowledge and/or skills that the subjects possessed in the field which makes the feedback provided by the subjects towards the hypothetical case study carries more credibility if compared to subjects with little or no engineering knowledge at all. The data collected were then key-in and analyzed using Microsoft Excel to search for keywords and then categorized in according to the technical and non-technical risk factors group. Frequency of feedback occurrences by the subjects were also checked to get the overall picture on how the subjects perceived risks in respect to sustainable coastal development. The frequencies are then represented in a hierarchy as part of the result analysis. In addition, these technical and non-technical factors were then analyzed once again to find the common aspects and/or characteristics that they may share, in which will enable the factors to be categorized into the respective themes reviewed earlier, but not limited to these themes only. This is because some of the factors may prompt a new theme to be designed for the weight and importance that these factors carry. Lastly, these factors and their respective theme were placed together to form a preliminary framework for future studies. 
The Third International Conference on Civil Engineering Research (ICCER)

August $1^{\text {st }}-2^{\text {nd }} 2017$, Surabaya - Indonesia

\section{RESULTS AND ANALYSIS}

A variety of perspectives were expressed by the respondents towards the scenario posed through the hypothetical case study. Keywords extracted from the responses provided by the subjects are recorded in Microsoft Excel and descriptive statistical analysis was then used to evaluate the common aspects and characteristics of these keywords which then assisted in the formation of group or theme of respective technical and non-technical risk factors.

\subsection{Technical Risk Factors}

There are fifteen (15) technical risk factors obtained from the responses which can be seen in Table $\mathbf{1}$. It is interesting to note that environmental based theme seemed to be the most dominant type of risk factors quoted by the respondents in which risk factors such as "pollution \& waste management", "environmental analysis", "preservation \& conservation" and "natural landscape \& phenomena" all forming $47.00 \%$ of the overall risk factors distribution. Disaster risk related risk factor was the fifth preferred factor with $8.44 \%$ occurrences. Physical based theme such as "construction "structural engineering" $(2.37 \%)$ are $8^{\text {th }}, 10^{\text {th }}, 11^{\text {th }}$ and $13^{\text {th }}$ on the list.

\subsubsection{Categorization of Technical Risk Factors}

In order the categorize the risk factors in accordance to their corresponding theme, the common aspects of risk factors were analyzed based on the literatures referred along with the association and familiarity of the keywords in the risk factors to one another. For example, responses given by the subjects consisting the word "environment" or "environmental" are classified as "environmental analysis" which then form the subset of environmental theme of technical risk factor. Summary of the technical factors in accordance to theme are as follows:

- Environmental (56.00\%) - Pollution \& Waste Management, Environmental Analysis, Preservation \& Conservation, Natural Landscape \& Phenomena, Weather \& Climate, and Water \& Coastal;

- Technology (7.97\%) - Technology Applications and Green Technology;

- Physical (18.03\%) - Construction \& Building Materials, Geographical Analysis, Infrastructure Management, and Structural Engineering;

Table 1.

Technical Risk Factors for Sustainable Coastal Development

\begin{tabular}{ccc}
\multicolumn{3}{c}{ Technical Risk Factors for Sustainable Coastal Development } \\
\hline Risk Factors & Frequency & Percentage (\%) \\
\hline Pollution \& Waste Management & 147 & $13.95 \%$ \\
Environmental Analysis & 137 & $13.00 \%$ \\
Preservation \& Conservation & 122 & $11.57 \%$ \\
Natural Landscape \& Phenomena & 93 & $8.82 \%$ \\
Disaster Risk & 89 & $8.44 \%$ \\
Technology Applications & 67 & $6.36 \%$ \\
Safety Issues & 66 & $6.26 \%$ \\
Construction \& Building Materials \\
Weather \& Climate
\end{tabular}

\& building methods" (6.17\%), geographical analysis $(5.03 \%)$, "infrastructure management" (4.46\%), and
- Health \& Safety (18.12\%) - Disaster Risk, Safety Issues and Natural Hazard. 
The Third International Conference on Civil Engineering Research (ICCER)

August $1^{\text {st }}-2^{\text {nd }}$ 2017, Surabaya - Indonesia

\subsection{Non- Technical Risk Factors}

There are fifteen (15) non-technical risk factors constructed from the subjects' responses which is shown as in Table 2. Economic based risk factors such as "cost control", "financial management", "economic study" as well as "resources management" were found to be the most dominant factors quoted by the respondents in regard to non-technical risk factors for sustainable coastal development. These factors accounted for approximately $54.00 \%$ out of the overall non-technical factors in which the "cost control" factor amounting for $26.61 \%$ of that total amount. Moreover, "policy \& regulations" factor was also considered as worthy mention as this factor appeared to be the third most quoted risk factor by the respondents with $8.60 \%$ occurrences. Social based theme for factors such as "social issues", "human \& population" and "cultural \& heritage" were also considered as quite vital for disaster risk management as these factors all together contributed to $15.70 \%$ from the overall non-technical risk factors

\subsubsection{Categorization of Technical Risk Factors}

In order the categorize the risk factors in accordance to technical risk factors were also conducted. Through the multiple literatures referred and reviewed earlier, nontechnical risk factors usually come from economic, social, socio-cultural, socio-economic and organizational themes. For example, words such as "economic" and "economy" given by the respondents are classified as "economic study" which then categorized under the economic theme. Summary of the non-technical factors in accordance to their corresponding themes are as follows:

- Economic (54.00\%) - Cost Control, Financial Management, Economic Study and Resources Management;

- Organizational (26.29\%) - Policy \& Regulations, Ethics \& Values, Project Management, Leadership and Development review;

- Socio-Cultural (15.53\%) - Social Issues, Human \& Population and Culture \& Heritage;

- Education (4.30\%) - Mitigation Measures, Society Education and Research.

Although education theme had a merely $4.30 \%$ occurrences for the overall non-technical risk factors, it

Table 2 .

belie

ved

that

Non-Technical Risk Factors for Sustainable Coastal Development spec

\begin{tabular}{|c|c|c|}
\hline Risk Factors & Frequency & Percentage $(\%)$ \\
\hline Cost Control & 161 & $26.61 \%$ \\
\hline Financial Management & 84 & $13.88 \%$ \\
\hline Policy \& Regulations & 52 & $8.60 \%$ \\
\hline Ethics \& Values & 47 & $7.77 \%$ \\
\hline Social Issues & 46 & $7.60 \%$ \\
\hline Economic Study & 42 & $6.94 \%$ \\
\hline Resources Management & 39 & $6.45 \%$ \\
\hline Human \& Population & 38 & $6.28 \%$ \\
\hline Project Management & 37 & $6.12 \%$ \\
\hline Mitigation Measures & 19 & $3.14 \%$ \\
\hline Leadership & 14 & $2.31 \%$ \\
\hline Culture \& Heritage & 10 & $1.65 \%$ \\
\hline Development Review & 9 & $1.49 \%$ \\
\hline Society Education & 5 & $0.83 \%$ \\
\hline Research & 2 & $0.33 \%$ \\
\hline
\end{tabular}

atten tion shou 
The Third International Conference on Civil Engineering Research (ICCER)

August $1^{\text {st }}-2^{\text {nd }}$ 2017, Surabaya - Indonesia

\section{DISCUSSION}

This research paper was established to identify the technical and non-technical risk factors pertaining to sustainable coastal development. Based on the results and analysis demonstrated, it was proven that there are multiple risk factors considered by the respondents via the hypothetical case study conducted. Due to the diverse nature of the responses provided, categorization of the risk factors into technical and non-technical category and into respective theme such as environmental, social, economic or physical proved to be a challenging task. For technical category, four themes were assigned to this type of risk factor which are environmental, physical, health \& safety and technology. As for non-technical category, another four themes were also assigned to the risk factors which are economic, organizational, social and education. Occupying these themes, fifteen risk factors were allocated to both types of disaster risk.

The most interesting finding was that, for technical factors, environmental type of risk factors was found to be the most dominant risk factors stated by the respondents with $56.00 \%$ total occurrences throughout the sampling data. This situation comes quite as a surprise given that physical based factors such as structural engineering, infrastructure management, geographical analysis and construction \& building materials which received only $18.03 \%$ in total occurrences were perceived to have less of a risk given its close nature to pure engineering field as well as the risk factors towards disaster risk management in regard to sustainable coastal development where both factors receiving worthy occurrences of $11.86 \%$ in combine. Safety issues were also of a concern where the participants perceived safety factors such as human safety and worker's safety among the noteworthy risk factors with $6.26 \%$ occurrences. Together, these three factors made up the health \& safety theme with $18.12 \%$ occurrences throughout the overall sampling data. Technology-based theme with $7.97 \%$ occurrences made up the rest of technical factors with subjects generally concerned with using technological applications to manage disaster risk via warning system, automation, waste management technology and green technology.

For non-technical factors, the subjects are generally concerned with cost related risk with approximately $26.00 \%$ of the responses received were categorized as cost control factor. Along with this factor, the rest of the economic based factors recorded a sizeable 54.00\% occurrences throughout the overall sampling data. Organizational based risk factors are also a worthy mention where policy \& regulations was perceived as vital by the respondents with $8.60 \%$ mentions. Social based factors were combined with cultural based factors to form socio-cultural theme due to the interconnectedness of these two themes to one another. Education theme was also presented as risk factor as it is believed that this factor can play an important role in disaster risk management.

Summary of both technical and non-technical risk

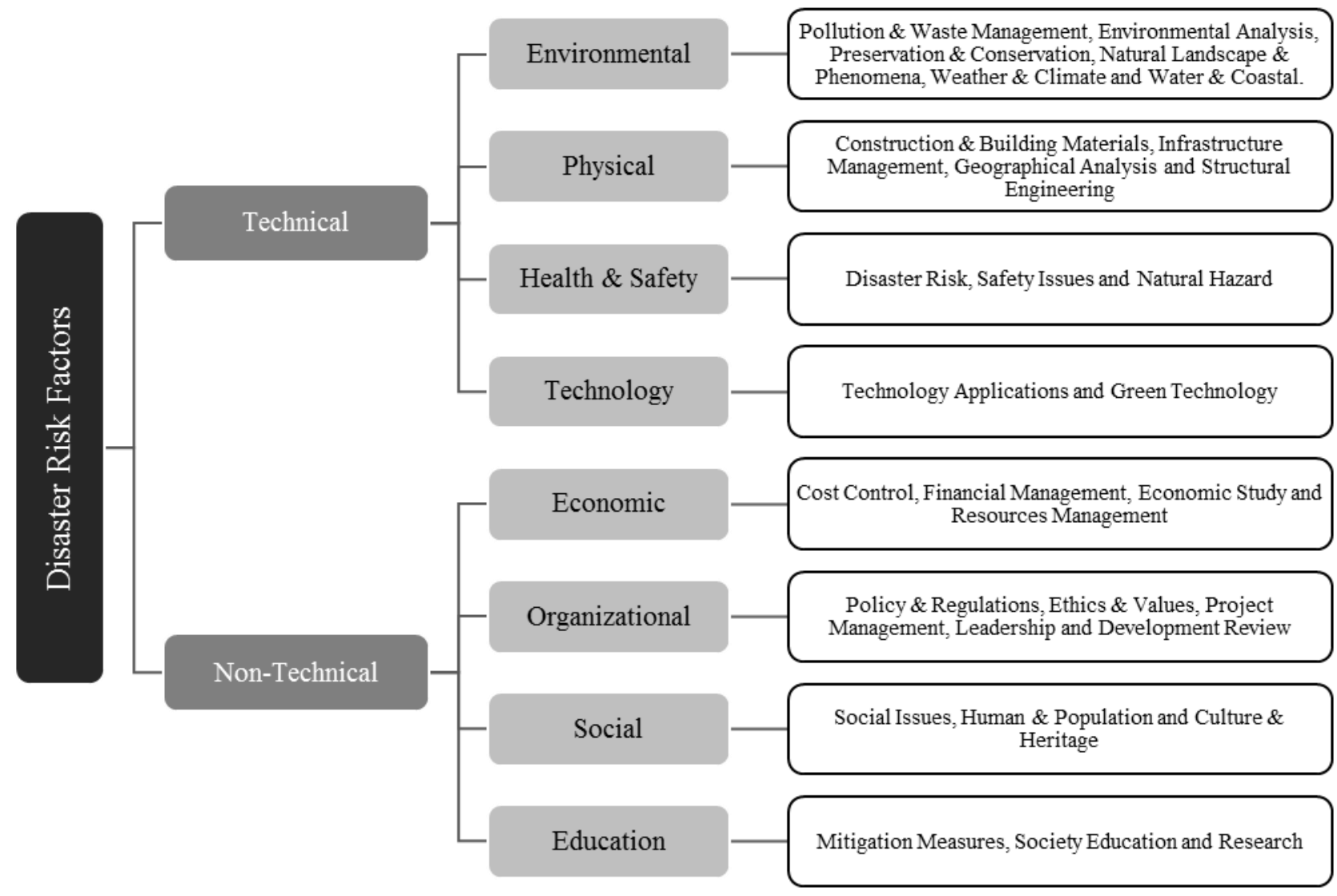

Figure 1. Proposed Preliminary Framework for Technical and Non-Technical Factors of Disaster Risk

sample's characteristics. However, the subjects did recognize the importance of natural hazard and disaster factors can be seen in Figure 1 where a preliminary framework for risk identification in regard to sustainable 
The Third International Conference on Civil Engineering Research (ICCER)

August $1^{\text {st }}-2^{\text {nd }}$ 2017, Surabaya - Indonesia

coastal development was proposed. The risk factors were first segregated into technical and non-technical related category before being divided into respective themes. It can be observed that technical risk factors consist of environmental, physical, health \& safety and technology themes in which detailed list of associated risk factors were also assigned to each risk theme. On the other hand, economic, organizational, socio-cultural as well as education are attached to the non-technical risk factors, with associated detailed list of factors were also assigned to each risk theme. It is vital to highlight that this framework is envisioned to be used as a tool or a model to identify the technical and non-technical factors for sustainable coastal development as the research paper intended to. Also, due to its nature of being at the preliminary stage, further refinements to the framework is possible in the near future in order to come up with a better version.

\section{CONCLUSION}

Identifying and determining the risk factors will enable communities and policy makers to make well-informed decisions for long term sustainable development which represents national and local priorities with a strong institutional basis for implementation. Building on the existing literatures on disaster risk factors, this research has provided a platform for risk factors identification in which the factors were divided into two main groups technical and non-technical. Categorization of the risk factors in these two main groups into corresponding type or theme was done by finding and analyzing the common aspects and characteristics that these factors seem to share between one another.

Hypothetical case study approach was used in this study which seek to utilize open-ended feedback from the respondents where they were required to list five factors that they considered as crucial to ensure project success in a sustainable coastal development without advanced notification or existence of pre-determined factors. Thus, this study has explored various insights and perspectives for both technical and non-technical factors. Based on this approach, it allowed for categorization of these risk factors into their respective common aspects or theme. Findings indicated that environmental, technology, health \& safety and physical related risk factors were identified and categorized as technical-based factors while economic, socio-cultural, organizational and education were identified and categorized as non-technical based factors pertaining sustainable coastal development. In order to put these results into a more holistic perspective and represent them in a more user-friendly way, a preliminary framework of technical and non-technical risk factors for sustainable coastal development was developed and proposed as presented in Figure 1. It is hoped that this preliminary framework will be able to add to the existing body of knowledge for disaster risk factors as well as provide a basis for risk factors identification for disaster risk management research and application.

However, extensive research on the topic is of course needed in order to come up with an improved version of the proposed framework. As this research paper was meant to identify technical and non-technical risk factors regarding sustainable coastal development, the scope of this research paper is limited to this particular area of knowledge only. It is solely meant to provide a basis for such effort as this study considers this topic has not been widely addressed. Therefore, continuous efforts should also be carried out to investigate how these factors may or may not affect the disaster risk mitigation or reduction efforts. As pointed in the Discussion section, it is also interesting to note that the participants with sound engineering knowledge perceived environmental and economic pertaining risk factors as the most significant types of risk that need to be managed to ensure project success as opposed to the popular believes that physical related factors such as engineering measures and technical study will be nominated as the preferred risk factors. Future study on this thought-provoking situation can be carried out to find the root causes.

\section{REFERENCES}

[1] F. Bendimerad, "Disaster Risk Reduction and Sustainable Development," World Bank Semin. Role Local Gov. Reducing Risk Disaster., vol. 2000, pp. 57-75, 2003.

[2] N. W. Chan, "Impacts of disasters and disasters risk management in Malaysia: The case of floods," Econ. Welf Impacts Disasters East Asia Policy Responses., no. December, pp. 503-551, 2012.

[3] Ministry of Natural Resources \& Environment, "Flood and Drought Management in Malaysia," Kuala Lumpur, 2007.

[4] S. G. D/iya, M. B. Gasim, M. E. Toriman, and M. G. Abdullahi, "Floods in Malaysia: Historical Reviews, Causes, Effects and Mitigations Approach," Int. J. Interdiscip. Res. Innov., vol. 2 no. 4, pp. 59-65, 2014.

[5] NADMA, "Portal Bencana," Arahan Majlis Keselamatan Negara No. 20: Dasar dan Mekanisme Pengurusan Bencana, 2012. [Online]. Available: http://portalbencana.ndcc.gov.my/Portal/Board/Detail?board=13 7\&entity=7321. [Accessed: 02-May-2017].

[6] C. Small and R. J. Nicholls, "A Global Analysis of Human Settlement in Coastal Zones," J. Coast. Res., vol. 19, no. 3, pp. 584-599, 2003.

[7] D. Coventry, "World Resources 2000-2001: People and Ecosystems: The Fraying Web of Life," Agric. Ecosyst. Environ., vol. 86, no. 1, pp. 109-110, 2001.

[8] United Nations, "Sendai Framework for Disaster Risk Reduction (2015-2030)," pp. 9-36, 2015.

[9] UNISDR, "2009 UNISDR Terminology on Disaster Risk Reduction," Int. Strat. Disaster Reduct., pp. 1-30, 2009.

[10] World Bank, "Understanding risk: The evolution of disaster risk assessment," 2014.

[11] IPCC, Managing the risks of extreme events and disasters to advance climate change adaptation. 2012

[12] B. L. Turner et al., "A framework for vulnerability analysis in sustainability science," Proc. Natl. Acad. Sci. United States Am. vol. 100 , no. 14 , pp. 8074-8079, 2003.

[13] B. Wisner, P. Blaikie, T. Cannon, and I. Davis, "At Risk: Natural Hazards, People's Vulnerability, and Disasters," Hum. Ecol., vol. 24, no. 1, pp. 141-145, 1996.

[14] M. L. Carreño, O. D. Cardona, and A. H. Barbat, "Urban seismic risk evaluation: A holistic approach," Nat. Hazards, vol. 40, no. 1, pp. 137-172, 2007.

[15] United Nations, Living with risk: a global review of disaster reduction initiatives, vol. 1. 2004.

[16] R. A. Davidson and H. C. Shah, "An Urban Earthquake Disaster Risk Index," 1997.

[17] C. Bollin, C. Cardenas, H. Hahn, and K. S. Vatsa, Disaster Risk Management by Communities and Local Governments. 2006

[18] J. J. Bogardi and J. Birkmann, "Vulnerability assessment: the first step towards sustainable risk reduction," in Disasters and society : from hazard assessment to risk reduction, Berlin: Logos Verlag Berlin, 2005, pp. 1-83.

[19] O. D. Cardona, "Environmental management and disaster prevention: Two related topics: A holistic risk assessment and 
management approach," Nat. disaster Manag., pp. 151-153, 1999.

[20] J. L. Nicolodi and R. M. Petermann, "Potential vulnerability of the Brazilian coastal zone in its environmental, social, and technological aspects," Panam. J. Aquat. Sci., vol. 5, no. 2, pp. 184-204, 2010.

[21] E. Lioubimtseva and G. M. Henebry, "Climate and environmental change in arid Central Asia: Impacts, vulnerability, and adaptations," Journal of Arid Environments, vol. 73, no. 11. pp. 963-977, 2009.

[22] J. Toro, O. Duarte, I. Requena, and M. Zamorano, "Determining Vulnerability Importance in Environmental Impact Assessment. The case of Colombia," Environ. Impact Assess. Rev., vol. 32, no. 1, pp. 107-117, 2012.

[23] G. Yoo, A. R. Kim, and S. Hadi, "A methodology to assess environmental vulnerability in a coastal city: Application to Jakarta, Indonesia," Ocean Coast. Manag., vol. 102, no. PA, pp. 169-177, 2014.

[24] H. Khan, L. Vasilescu, and A. Khan, "Disaster management cycle - a theoretical approach," Manag. Mark. J., vol. 6, no. 1, pp. 43-50, 2008.

[25] M. N. Hossain, "Analysis of human vulnerability to cyclones and storm surges based on influencing physical and socioeconomic factors: Evidences from coastal Bangladesh," Int. J. Disaster Risk Reduct., vol. 13, pp. 66-75, 2015.

[26] S. F. Jenkins, R. J. S. Spence, J. F. B. D. Fonseca, R. U. Solidum, and T. M. Wilson, "Volcanic risk assessment: Quantifying physical vulnerability in the built environment," $J$. Volcanol. Geotherm. Res., vol. 276, pp. 105-120, 2014.
[27] M. Papathoma-Köhle, M. Kappes, M. Keiler, and T. Glade, Physical vulnerability assessment for alpine hazards: State of the art and future needs, vol. 58, no. 2. 2011.

[28] J. Douglas, "Physical vulnerability modelling in natural hazard risk assessment," Nat. Hazards Earth Syst. Sci., vol. 7, no. 2, pp 283-288, 2007.

[29] S. M. Tapsell, E. C. Penning-Rowsell, S. M. Tunstall, and T. L. Wilson, "Vulnerability to flooding: health and social dimensions," Philos. Trans. R. Soc. London A Math. Phys. Eng. Sci., vol. 360, no. 1796, pp. 1511-1525, 2002.

[30] E. Marzo, V. Busini, and R. Rota, "Definition of a short-cut methodology for assessing the vulnerability of a territory in natural-technological risk estimation," Reliab. Eng. Syst. Saf., vol. 134, pp. 92-97, 2015.

[31] S. McLaughlin, J. McKenna, and J. A. G. Cooper, "Socioeconomic data in coastal vulnerability indices: constraints and opportunities," J. Coast. Res., no. September 2002, pp. 487-497, 2002.

[32] D. Felsenstein and M. Lichter, "Social and economic vulnerability of coastal communities to sea-level rise and extreme flooding," Nat. Hazards, vol. 71, no. 1, pp. 463-491, 2014.

[33] G. Brewer, A. Mcveigh, and J. Von Meding, "An Evaluation of the Usefulness of Actor Network Theory in Understanding the Complexities of Vulnerability and Resilience in Post-Disaste Reconstruction," Int. J. Archit. Res., vol. 7, no. 3, pp. 80-92, 2013.

[34] B. E. Flanagan, E. W. Gregory, E. J. Hallisey, J. L. Heitgerd and B. Lewis, "A Social Vulnerability Index for Disaster Management," J. Homel. Secur. Emerg. Manag., vol. 8, no. 1 , 2011.

[35] H. Baytiyeh, "Socio-cultural characteristics: the missing factor in disaster risk reduction strategy in sectarian divided societies," Int. J. Disaster Risk Reduct., vol. 21, no. November 2016, pp. 63-69, 2017.

[36] R. K. Yin, "Case Study Reserach - Design and Methods," Clin Res., vol. 2, pp. 8-13, 2006. 